\title{
Personality and eating and weight disorders: an open research challenge
}

\author{
Santino Gaudio ${ }^{1} \mathbb{D} \cdot$ Antonios Dakanalis $^{2}$
}

Received: 4 November 2017 / Accepted: 8 November 2017 / Published online: 24 November 2017

๑) Springer International Publishing AG, part of Springer Nature 2017

\section{Introduction}

The editorial focuses on the relationships between personality and eating and weight disorders (EWDs), and aims to briefly document the progress in this field, bringing new contributions and future research directions to several queries that remain open in the existing literature. It introduces the Topical Collection "Personality and Eating and Weight Disorders" which will cover contributions aiming at further improving our knowledge about the role of personality (traits and disorders) in the pathogenesis, symptomatic expression, clinical course, persistence and treatment outcome of eating disorders (i.e., anorexia nervosa, bulimia nervosa, and binge-eating disorder), other specified feeding and eating disorders recognized in DSM-5 [1] (i.e., atypical anorexia nervosa, bulimia nervosa and binge-eating disorder of low frequency and/or limited duration, and purging disorder), and obesity. In addition to increasing awareness in the scientific community on the role of personality in EWDs, the topical collection is aimed at providing a wide evidence base for researchers, clinicians, and all readers interested in this topic.

\section{Personality and eating and weight disorders: the state of the art}

The aetiology of EWDs is still not fully understood and extant treatment strategies still need to be improved [2-10]. In the last 2 decades, many research groups have focused on the role of personality in EWDs, with recent systematic and meta-analytic reviews of the literature highlighting the common comorbidity of personality disorders (PDs) in EWDs and suggesting the impact of personality (traits and disorders) in EWDs clinical course and treatment outcome [11-13].

To date, it is known that the most frequent specific PD diagnoses in both adults [11-14] and adolescents $[15,16]$ with EWDs are the avoidant, obsessive-compulsive, and borderline PDs. In addition, the avoidant and obsessive-compulsive PDs are among the most frequently diagnosed PDs in restricting anorexia nervosa (AN-r), whereas borderline and avoidant PDs are commonly diagnosed in people with binge-eating/purging AN (AN-bp), bulimia nervosa (BN), binge-eating disorder (BED), and obesity [11-16]. People with EWDs tend to be characterized by elevated perfectionism, sensitivity to social rewards, impulsiveness, and affective instability, and these features appear to discriminate patients from controls [12, 13]. Differences across EWD conditions also seem to exist, with the current evidence revealing that perfectionism and fear of criticism are more recurrent in AN-r, whereas affective instability and emotional dysregulation are more evidenced in AN-bp and BN [13]. Although research on BED (recently recognized as a distinct diagnostic category in the DSM-5) is still limited [13], some studies suggested that (obese and nonobese) patients with BED endorse comparable levels of affective instability to those with $\mathrm{BN}[2,17,18]$, and indicated that this variable predicts BED and BN severity $[17,18]$. Impulsiveness, however, appears to be a key predictor for overweight and obesity development [12]. In addition, impulsiveness and altered emotional regulation seem to impact clinical symptoms in people with obesity [19] and severe obesity with food 
addiction [20]. Overall, AN-r is more frequent associated with Cluster C PDs (i.e., avoidant, dependent, and obsessive-compulsive) or their characteristic traits and the EWD conditions characterized by binge-eating and/or purging behaviours are more frequently associated Cluster B PDs (i.e., antisocial, borderline, histrionic, and narcissistic) or their characteristic traits [11-13, 15].

Interesting findings have been published regarding the role of personality disturbances in the aetiology and symptomatic expression of EWDs, with recent reviews of the literature highlighting that people with any PD have a higher risk of obesity [12] and that certain personality traits (e.g., perfectionism and impulsiveness) may increase the risk of developing eating disorders and disordered eating cognition and behaviours [4]. However, prospective studies remain few in EWD area and research elucidating whether personality has causal significance in the onset of specific EWDs is warranted $[4,11-13]$.

Several studies have evaluated the notion that personality traits and disorders influence the clinical course and treatment outcome of EWDs [21]. These studies revealed that Cluster B PDs seem to be related to a poorer AN and BN outcome and obsessive-compulsive PD traits are poor prognostic features among people with AN [21]. AN patients with a comorbid PD also show higher rates of inpatient treatment drop out [22] and altered personality traits may favour resistance and impair improvement in this group [23]. Although some studies suggest that a comorbid PD does not influence treatment result in BN [13], in other studies, personality seems to be a predictor of recovery in $\mathrm{BN}$ and sub-threshold forms of eating disorders [24]. PD comorbidity appears to affect weight loss under conservative treatments and Cluster B PDs seem to have a negative effect on long-term prognosis with regard to binge-eating symptoms [12]. Results on the impact of PD comorbidity on treatment outcome among (obese and non-obese) people with BED remain few and conflicting $[12,13]$. Overall, considering that personality evaluation may provide useful elements and information to define more suited treatment strategy [11-13], further studies are needed to better elucidate the role of personality traits and disorders in the clinical course and outcome of EWDs. Future investigations on this area may benefit from the fruitful and open debate on usefulness and reliability of various constructs and assessment tools in the personality field of research $[11,13]$.

\section{Multi-factor nature of eating and weight disorder and personality: a brief synopsis}

It is widely accepted that EWDs have a complex pathogenesis involving transactions among sociocultural, psychological, and neurobiological influences [4, 9, 25-29]. However, these transactions have received limited research attention, although several hypotheses have been advanced in the literature. For instance, Kaye and colleagues [26] argued that specific neurobiological factors, linked to specific childhood temperament and personality traits (i.e., anxiety, obsessions, and inflexibility), may create a vulnerability to developing AN. According to other scholars, AN patients seem to share familial liability factors, such as a trans-generational tendency for anxiety and specific personality features, which may be linked to fear and anxiety neuro-circuitry alterations and a familial vulnerability for AN [28]. Promising multivariate aetiological and maintenance models attempting to explain how certain personality traits work with other vulnerability factors to promote or maintain EWDs also provide valuable insights into the multi-factor nature of these clinical conditions [30]. Some models postulate a mediational sequence that links risk/maintenance factors developmentally, whereas others are interactive in nature (i.e., posit a particular confluence of factors in promoting or maintaining EWD pathology). For instance, besides the trans-diagnostic cognitive-behavioural model (for a description, see [30]), the multi-dimensional model of AN [31] postulates that biogenetic factors, family characteristics (like low independence), and individual personality factors (such as ineffectiveness and being a "perfect" or "model" child), interact to predict the onset of AN. Another influential model is the cumulative stressor model, which highlights the confluence of perfectionism, low self-esteem, and body dissatisfaction in promoting BN [32]. These multi-variate models, which informed the development of prevention and treatment programmes, received preliminary support [30] but should be tested with longitudinal designs that allow the demonstration of temporal precedence for each link in these accounts.

A recent study showed that social factors (e.g., media pressure) and specific personality traits (e.g., perfectionism) interact to predict disordered eating behaviours [33]. Another study showed that professional models are at a higher risk of developing negative automatic thoughts and dysfunctional assumptions relating to body weight, size, and shape if they endorse high scores on specific personality (e.g., narcissistic) styles [34]. In addition to the direct effect of narcissistic vulnerability (noted by a frail self-image, self-adequacy concerns, hypersensitivity to criticism, and withdrawal when narcissistic needs are not met) on future bulimic behaviours, narcissistic grandiosity (that best captures the representation of narcissistic PD) increases the likelihood of engaging in dieting behaviours, which in turn increases the likelihood of engaging in bulimic behaviours [35]. Certain personality traits, such as affective liability, are related to impulsive behaviours [36] and interact with elevated compulsivity to predict extreme exercise behaviours [37]. In both clinical and non-clinical samples [38, 39], perfectionism was found to interact with body dissatisfaction 
(i.e., an established risk and maintenance factor of EWDs [4, 40]) and insecure attachment to predict higher levels of dieting, binge-eating, and compensatory behaviours. Elevated serotonin reuptake in a clinical sample was related to higher perfectionism levels and lower rates of childhood sexual abuse, whereas reduced serotonin reuptake was related to higher rates of childhood sexual abuse and borderline PD [41]. These findings, as well as the aforementioned multivariate aetiological and maintenance models, suggest that, although it is fruitful to consider specific personality traits and disorders alone [42-51], the consideration of interrelations between personality and bio-psychosocial factors is vital for elucidating the complex and multifactorial pathogenesis of EWDs.

\section{Conclusions and future directions}

The current research indicates that PDs are highly comorbid in EWDs and suggests that meaningful variance in the development, clinical course, symptomatic profile, and treatment outcome of EWDs could be explained by personality traits and disorders [4, 11-14, 16, 21]. However, a deeper and careful examination of the links between personality and EWDs is warranted. This would allow us to better understand the onset, severity and persistence of EWDs, incorporate and target specific personality variables in treatment, and develop more effective ways of matching treatment to EWD patients [11-13, 16].

Among the possible future directions in this field of research, three open questions can be considered as primary. The first is whether specific personality disorders or traits serve as risk factors for EWD onset and clinical presentations. Additional related issues with important theoretical and clinical implications that deserve research attention are the evaluation of: (1) how certain personality traits work with other vulnerability factors (i.e., psychosocial) to promote and/or maintain EWDs and (2) the role of personality in the cross-over between different EWD conditions [4, $11,13]$. Longitudinal research is needed to elucidate these points, which may be crucial in the treatment planning process. In this context, the debate on usefulness and reliability of personality assessment in adolescence [14, 16, 52], the period of life which has the highest rate of onset of EWDs [4], remains open. Although extant current studies with adolescent samples are few [11], there is some evidence that the proportion and characteristics of comorbid PDs in adults with EWDs converges with those reported amongst adolescent patients (e.g., $[15,16])$ and that late adolescents with a comorbid PD have a more severe ED [15]. Further evidence on the usefulness and reliability of personality assessment in adolescence and/or efforts towards the development of more adolescent-sensitive assessment tools are needed [16,
52]. In addition, further longitudinal studies enrolling people with different EWDs from adolescence are needed to explore the role of personality in EWDs development and course $[16,52]$. The second open question is whether and how specific neurobiological factors, linked to specific personality and temperament traits, may create vulnerability to developing an EWD and/or affect outcome [26]. Although PDs have been considered as possible confounding factors in neuroimaging investigations (e.g., [53]), thus far, neuroimaging research has not explored neural bases in EWD samples with and without PDs and/or heightened personality traits. This approach could give new and useful insight in understanding the complex pathophysiology of EWDs and the personality-EWD relationship. The third open question is whether the (already mentioned) rates of PD comorbidity in EWD patients identified based on DSM-IV criteria change when the new DSM-5 criteria [1] are applied. Research also needs to investigate PD comorbidity as well as the stability and predictive value of personality among people with DSM-5 [1] atypical AN, BN and BED of low frequency and/or limited duration, and purging disorder. In addition, research linking personality and EWDs amongst men and people with different ethnicity/race is needed [33, 54, 55], since the majority of extant studies in this area have focused on female Caucasian samples [13].

We hope that the Topical Collection: (1) will amplify alertness in the scientific community on the role of personality (disorders and traits) in the aetiology, symptomatic expression, clinical course, and outcome of all forms of eating disorders recognized in DSM-5 [1] and obesity; and (2) will give an important hub for scientific discussion based on empirical data investigating different perspectives (from neurobiological to psychometric) of personality disturbances in EWDs. We expect that the topical collection will provide interesting new insights and a wide evidence base for researchers, clinicians, and all readers interested in the area of personality and EWDs.

\section{Compliance with ethical standards}

Conflict of interest The authors state that there is no conflict of interest.

Ethical approval This article does not contain any studies with human participants or animals performed by any of the authors.

Informed consent For this type of study, formal consent is not required.

\section{References}

1. American Psychiatric Association (2013) Diagnostic and statistical manual of mental disorders, 5th edn. American Psychiatric Association, Washington 
2. Dakanalis A, Carrà G, Calogero R, Zanetti MA, Gaudio S, Caccialanza R, Riva G, Clerici M (2015) Testing the cognitivebehavioural maintenance models across DSM-5 bulimic-type eating disorder diagnostic groups: a multi-study. Eur Arch Psychiatry Clin Neurosci 265(8):663-776. https://doi.org/10.1007/ s00406-014-0560-2

3. Dakanalis A, Gaudio S, Serino S, Clerici M, Carrà G, Riva G (2016) Body-image distortion in anorexia nervosa. Nat Rev Dis Primers 2:16026. https://doi.org/10.1038/nrdp.2016.26

4. Culbert KM, Racine SE, Klump KL (2015) Research review: what we have learned about the causes of eating disorders-a synthesis of sociocultural, psychological, and biological research. J Child Psychol Psychiatry 56:1141-1164. https://doi.org/10.1111/ jcpp. 12441

5. Mitchell JE, Agras S, Wonderlich S (2007) Treatment of bulimia nervosa: where are we and where are we going? Int J Eat Disord 40:95-101. https://doi.org/10.1002/eat.20343

6. Serino S, Pedroli E, Keizer A, Triberti S, Dakanalis A, Pallavicini F, Chirico A, Riva G (2016) Virtual reality body swapping: a tool for modifying the allocentric memory of the body. Cyberpsychol Behav Soc Netw 19(2):127-133. https://doi.org/10.1089/ cyber.2015.0229

7. Dakanalis A, Carrà G, Timko A, Volpato C, Pla-Sanjuanelo J, Zanetti A, Clerici M, Riva G (2015) Mechanisms of influence of body checking on binge eating. Int J Clin Health Psychol 15(2):93-104. https://doi.org/10.1016/j.ijchp.2015.03.003

8. Ágh T, Kovács G, Supina D, Pawaskar M, Herman BK, Vokó Z, Sheehan DV (2016) A systematic review of the health-related quality of life and economic burdens of anorexia nervosa, bulimia nervosa, and binge eating disorder. Eat Weight Disord 21(3):353364. https://doi.org/10.1007/s40519-016-0264-x

9. Zipfel S, Giel KE, Bulik CM, Hay P, Schmidt U (2015) Anorexia nervosa: aetiology, assessment, and treatment. Lancet Psychiatry 2:1099-1111. https://doi.org/10.1016/S2215-0366(15)00356-9

10. Kass AE, Kolko RP, Wilfley DE (2013) Psychological treatments for eating disorders. Curr Opin Psychiatry 26(6):549-555. https:// doi.org/10.1097/YCO.0b013e328365a30e

11. Martinussen $M$, Friborg $O$, Schmierer $P$, Kaiser $S$, Øvergård KT, Neunhoeffer AL, Martinsen EW, Rosenvinge JH (2017) The comorbidity of personality disorders in eating disorders: a meta-analysis. Eat Weight Disord 22(2):201-209. https://doi. org/10.1007/s40519-016-0345-x

12. Gerlach G, Loeber S, Herpertz S (2016) Personality disorders and obesity: a systematic review. Obes Rev 17(8):691-723. https://doi. org/10.1111/obr.12415

13. Farstad SM, McGeown LM, von Ranson KM (2016) Eating disorders and personality, 2004-2016: A systematic review and metaanalysis. Clin Psychol Rev 46:91-105. https://doi.org/10.1016/j. cpr.2016.04.005

14. Rosenvinge JH, Friborg O, Kaiser S, Martinussen M (2017). Catching the moving target of adolescent personality and its disorders. A commentary on the article (doi:10.1007/s40519-0170368-y) by Gaudio and Dakanalis: What about the assessment of personality disturbance in adolescents with eating disorders? Eat Weight Disord. https://doi.org/10.1007/s40519-017-0402-0

15. Gaudio S, Di Ciommo V (2011) Prevalence of personality disorders and their clinical correlates in outpatient adolescents with anorexia nervosa. Psychosom Med 73(9):769-774. https://doi. org/10.1097/PSY.0b013e318235b9b5

16. Gaudio S, Dakanalis A (2017) What about the assessment of personality disturbance in adolescents with eating disorders?. Eat Weight Disord. https://doi.org/10.1007/s40519-017-0368-y

17. Dakanalis A, Clerici M, Riva G, Carrà G (2017) Testing the DSM-5 severity indicator for bulimia nervosa in a treatmentseeking sample. Eat Weight Disord 22(1):161-167. https://doi. org/10.1007/s40519-016-0324-2
18. Dakanalis A, Colmegna F, Riva G, Clerici M (2017) Validity and utility of the DSM-5 severity specifier for binge-eating disorder. Int J Eat Disord 50(8):917-923. https://doi.org/10.1002/ eat. 22696

19. Micanti F, Iasevoli F, Cucciniello C, Costabile R, Loiarro G, Pecoraro G, Pasanisi F, Rossetti G, Galletta D (2017) The relationship between emotional regulation and eating behaviour: a multidimensional analysis of obesity psychopathology. Eat Weight Disord 22(1):105-115. https://doi.org/10.1007/s40519-016-0275-7

20. Ouellette AS, Rodrigue C, Lemieux S, Tchernof A, Biertho L, Bégin C (2017) An examination of the mechanisms and personality traits underlying food addiction among individuals with severe obesity awaiting bariatric surgery. Eat Weight Disord. https://doi. org/10.1007/s40519-017-0440-7

21. Lilenfeld LR, Wonderlich S, Riso LP, Crosby R, Mitchell J (2006) Eating disorders and personality: A methodological and empirical review. Clin Psychol Rev 26:299-320. https://doi.org/10.1016/j. cpr.2005.10.003

22. Pham-Scottez A, Huas C, Perez-Diaz F, Nordon C, Divac S, Dardennes R, Speranza M, Rouillon F (2012) Why do people with eating disorders drop out from inpatient treatment?: the role of personality factors. J Nerv Ment Dis 200(9):807-813. https:// doi.org/10.1097/NMD.0b013e318266bbba

23. Amianto F, Spalatro A, Ottone L, Daga GA, Fassino S (2017) Naturalistic follow-up of subjects affected with anorexia nervosa 8 years after multimodal treatment: Personality and psychopathology changes and predictors of outcome. Eur Psychiatry 45:198206. https://doi.org/10.1016/j.eurpsy.2017.07.012

24. Levallius J, Roberts BW, Clinton D, Norring C (2016) Take charge: Personality as predictor of recovery from eating disorder. Psychiatry Res 246:447-452. https://doi.org/10.1016/j. psychres.2016.08.064

25. Dakanalis A, Riva G (2013) Mass media, body image and eating disturbances: the underlying mechanism through the lens of the objectification theory. In: Sams LB, Keels JA (eds) Handbook on body image: gender differences, sociocultural influences and health implications, 1st edn. Nova Science, New York, pp 217-235

26. Kaye WH, Wierenga CE, Bailer UF, Simmons AN, BischoffGrethe A (2013) Nothing tastes as good as skinny feels: the neurobiology of anorexia nervosa. Trends Neurosci 36(2):110-120. https://doi.org/10.1016/j.tins.2013.01.003

27. Dakanalis A, Timko A, Serino S, Riva G, Clerici M, Carrà G (2016) Prospective psychosocial predictors of onset and cessation of eating pathology amongst college women. Eur Eat Disord Rev 24(3):251-256. https://doi.org/10.1002/erv.2433

28. Strober M, Freeman R, Lampert C, Diamond J (2007) The association of anxiety disorders and obsessive compulsive personality disorder with anorexia nervosa: evidence from a family study with discussion of nosological and neurodevelopmental implications. Int J Eat Disord 40:S46-S51. https://doi.org/10.1002/eat.20429

29. Caslini M, Bartoli F, Crocamo C, Dakanalis A, Clerici M, Carrà G (2016) Disentangling the association between child abuse and eating disorders: a systematic review and meta-analysis. Psychosom Med 78(1):79-90. https://doi.org/10.1097/ PSY.0000000000000233

30. Pennesi JL, Wade TD (2016) A systematic review of the existing models of disordered eating: do they inform the development of effective interventions? Clin Psychol Rev 43:175-192. https://doi. org/10.1016/j.cpr.2015.12.004

31. Lyon ME, Chatoor I, Atkins D, Silber T, Mosimann J, Gray J (1997) Testing the hypothesis of a multidimensional model of anorexia nervosa in adolescents. Adolescence 32(125):101-111

32. Bardone AM, Joiner TE, Abramson LY, Heatherton TF (1999) Perfectionism, perceived weight status, and self-esteem interact to predict bulimic symptoms: a model of bulimic symptom 
development. J Abnorm Psychol 108:695-700. https://doi. org/10.1037/0021-843X.108.4.695

33. Sanchez-Ruiz MJ, El-Jor C, Kharma JA, Bassil M, Zeeni N (2017) Personality, emotion-related variables, and media pressure predict eating disorders via disordered eating in Lebanese university students. Eat Weight Disord doi. https://doi.org/10.1007/ s40519-017-0387-8

34. Blasczyk-Schiep S, Sokoła K, Fila-Witecka K, Kazén M (2016) Are all models susceptible to dysfunctional cognitions about eating and body image? The moderating role of personality styles. Eat Weight Disord 21(2):211-220. https://doi.org/10.1007/ s40519-015-0228-6

35. Dakanalis A, Clerici M, Carrà G (2016) Narcissistic vulnerability and grandiosity as mediators between insecure attachment and future eating disordered behaviors: a prospective analysis of over 2,000 freshmen. J Clin Psychol 72(3):279-292. https://doi. org/10.1002/jclp.22237

36. Anestis MD, Peterson CB, Bardone-Cone AM, Klein MH, Mitchell JE, Crosby RD, Wonderlich SA, Crow SJ, Le Grange D, Joiner TE (2009) Affective lability and impulsivity in a clinical sample of women with bulimia nervosa: The role of affect in severely dysregulated behavior. Int J Eat Disord 42:259-266. https://doi. org/10.1002/eat.20606

37. Brownstone LM, Fitzsimmons-Craft EE, Wonderlich SA, Joiner TE, Le Grange D, Mitchell JE, Crow SJ, Peterson CB, Crosby RD, Klein MH, Bardone-Cone AM (2013) Hard exercise, affect lability, and personality among individuals with bulimia nervosa. Eat Behav 14:413-419. https://doi.org/10.1016/j.eatbeh.2013.07.004

38. Dakanalis A, Timko CA, Zanetti MA, Rinaldi L, Prunas A, Carrà G, Riva G, Clerici M (2014) Attachment insecurities, maladaptive perfectionism, and eating disorder symptoms: a latent mediated and moderated structural equation modeling analysis across diagnostic groups. Psychiatry Res 215:176-184. https://doi. org/10.1016/j.psychres.2013.10.039

39. Dakanalis A, Favagrossa L, Clerici M, Prunas A, Colmegna F, Zanetti MA, Riva G (2015) Body dissatisfaction and eating disorder symptomatology: a latent structural equation modeling analysis of moderating variables in 18-to-28-year-old males. J Psychol 149(1):85-112. https://doi.org/10.1080/00223980.2013.842141

40. Dakanalis A, Carrà G, Clerici M, Riva G (2015) Efforts to make clearer the relationship between body dissatisfaction and binge eating. Eat Weight Disord 20(1):145-146. https://doi.org/10.1007/ s40519-014-0152-1

41. Steiger H, Gauvin L, Israel M, Kin NM, Young SN, Roussin J (2004) Serotonin function, personality-trait variations, and childhood abuse in women with bulimia spectrum eating disorders. J Clin Psychiatry 65:830-837. https://doi.org/10.4088/JCP. v65n0615

42. Guarnido AS, Cabrera FH, Osuna MP (2012) Eating disorder detection through personality traits and self-concept. Eat Weight Disord 17(4):e309-e313. https://doi.org/10.3275/8755

43. Sansone RA, Chu JW, Wiederman MW, Lam C (2011) Eating disorder symptoms and borderline personality symptomatology. Eat Weight Disord 16(2):e81-e85. https://doi.org/10.1007/ BF03325313
44. McCormick LM, Keel PK, Brumm MC, Watson DB, FormanHoffman VL, Bowers WA (2009) A pilot study of personality pathology in patients with anorexia nervosa: modifiable factors related to outcome after hospitalization. Eat Weight Disord 14(23):e113-e120. https://doi.org/10.1007/BF03327808

45. Hinrichsen H, Waller G, Dhokia R (2007) Core beliefs and social anxiety in the eating disorders. Eat Weight Disord 12(1):e14-e18. https://doi.org/10.1007/BF03327776

46. Nozaki T, Takao M, Takakura S, Koreeda-Arimura C, Ishido K, Yamada Y, Kawai K, Takii M, Kubo C (2006) Psychopathological features of patients with prolonged anorexia nervosa as assessed by the Minnesota multiphasic personality inventory. Eat Weight Disord 11(2):59-65. https://doi.org/10.1007/BF03327752

47. Elfhag K (2005) Personality correlates of obese eating behaviour: Swedish universities Scales of Personality and the Three Factor Eating Questionnaire. Eat Weight Disord 10(4):210-215. https:// doi.org/10.1007/BF03327487

48. Fassino S, Daga GA, Delsedime N, Busso F, Pierò A, Rovera GG (2005) Baseline personality characteristics of responders to 6-month psychotherapy in eating disorders: preliminary data. Eat Weight Disord 10(1):40-50. https://doi.org/10.1007/BF03353418

49. Larsson JO, Hellzen M (2004) Patterns of personality disorders in women with chronic eating disorders. Eat Weight Disord 9(3):200-205. https://doi.org/10.1007/BF03325067

50. Chung YI, Kim JK, Lee JH, Jung YC (2017) Onset of dieting in childhood and adolescence: implications for personality, psychopathology, eating attitudes and behaviors of women with eating disorder. Eat Weight Disord 22(3):491-497. https://doi. org/10.1007/s40519-016-0285-5

51. Stoeber J, Madigan DJ, Damian LE, Esposito RM, Lombardo C (2016) Perfectionism and eating disorder symptoms in female university students: the central role of perfectionistic self-presentation. Eat Weight Disord. https://doi.org/10.1007/ s40519-016-0297-1

52. Skodol AE (2014) Commentary: assessing personality disorder in adolescents from the perspective of DSM-5. Clin Psychol Sci Pr 21(1):84-90. https://doi.org/10.1111/cpsp.12058

53. Gaudio S, Quattrocchi CC, Piervincenzi C, Zobel BB, Montecchi FR, Dakanalis A, Riva G, Carducci F (2017) White matter abnormalities in treatment-naive adolescents at the earliest stages of anorexia nervosa: a diffusion tensor imaging study. Psychiatry Res Neuroimaging 266:138-145. https://doi.org/10.1016/j. pscychresns.2017.06.011

54. Dakanalis A, Pla-Sanjuanelo J, Caslini M, Volpato C, Riva G, Clerici M, Carrà G (2016) Predicting onset and maintenance of men's eating disorders. Int J Clin Health Psychol 16(3):247-255. https://doi.org/10.1016/j.ijchp.2016.05.002

55. Dakanalis A, Clerici M, Caslini M, Gaudio S, Serino S, Riva G, Carrà G (2016) Predictors of initiation and persistence of recurrent binge eating and inappropriate weight compensatory behaviors in college men. Int J Eat Disord 49(6):581-590. https://doi. org/10.1002/eat.22535 